\title{
Handshakes between Spirit of the Craftsman and Scientist's Spirit for Vocational Education
}

\author{
Wang Yanhua \\ Department of Tourism Management \\ Chongqing City Vocational College \\ Chongqing, China
}

\author{
Li Yong* \\ Laboratory of Industrial Internet of Things \& Intelligent \\ Instrument, Ministry of Education \\ Chongqing University of Posts and Telecommunications, \\ Chongqing, China \\ 023liyong@163.com
}

\begin{abstract}
The history of rise and fall of ancient Chinese craftsmen is briefly reviewed, and it is point out that craftsmanship can't be developed isolated from the skill cultivate of craftsman. Based on an idea that applies artificial intelligence scientific technology to craftsmen skill modeling, steps and movements for vocational education are presented. To increase the efficiency of vocational skill cultivating we recommend that not only top craftsmen are engaged as guidance teachers, but also modern artificial intelligence engineers are involved in the understanding and representation of craftsman skills which can only be sensed and not explained historically. As a result, the process of high level vocational skill cultivating becomes more and more achievable.
\end{abstract}

Keywords-Spirit of the Craftsman; Scientific technology; Artifical Inteligence; Professional skills modelling; Vocational Education

\section{INTRODUCTION}

The ancient Chinese craftsmen used to be unreachable peaks of skill and technology for thousands of years, who had achieved numerous amazing wonders even for nowadays world. In the last frustrating 100 years, Chinese goods are ridiculed as poor, cheap, and even fake ones, especially for the last 50 years. When German and Japanese are self-proud and admired for the quality of their goods, We need to reexamine the brilliant skill of Chinese craftsman.

There are numerous examples for thousands years. Which is most attractive to me is the production technology of Emperor Qin Shihuang. Archaeologists excavated more than 30 thousands of triangular arrowheads made of bronze under the yellow soil in the surrounding area of his still unexplored mausoleum, as show in Fig. 1. When some of them are measured with precision instrument, it is amazing that the error of each edge of arrowhead is less than $0.15 \mathrm{~mm}$ [1]. Although some people are concerned with the power of Qin Crossbow, it is fact that these weapons are pipelined produced according to strict standards. The locking lever and trigger of Qin crossbow are interchangeable between crossbows and the locking lever is used as a simple aiming device, as shown in Fig. 2.

Standardization is consensus for modern industry. But for Qing dynasty Army, which is at the historical corner of agrarian society and slave society, standardized weapons make them the strongest military power for the whole ancient Chinese history.

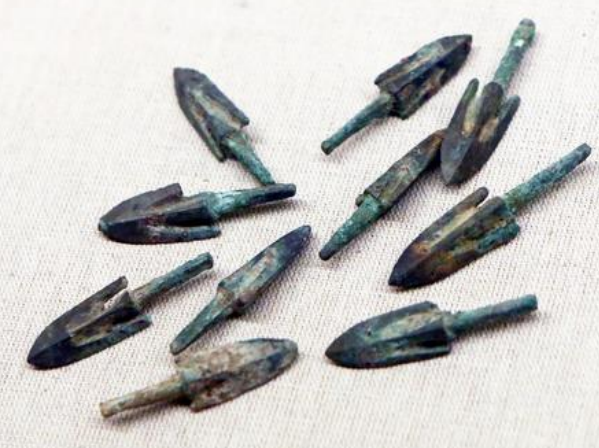

Fig. 1. Triangular bronze arrowheads of Qin dynasty excavated from Xian

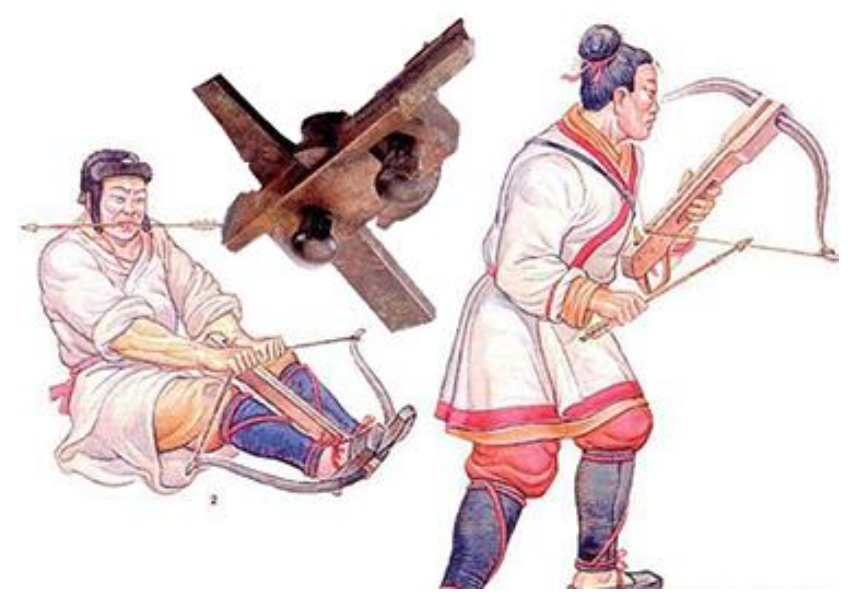

Fig. 2. Locking lever and trigger of Qin crossbow 
In a lot of occasions, news and reports, craftsmanship are prized and encouraged. It seems that craftsmanship is a refound key to the powerful modern industrial CHINA. By a brief analysis of Chinese ancient craftsman history, we point out that craftsmanship is on their destiny path of disappearance. But the sunshine of science technology, especially artificial intelligence, can supply the necessary power for craftsmanship survival and development. Handshakes between spirit of the craftsman and scientist's spirit is expected.

Nowadays, MADE IN CHINA is hotly expected, and looked forward to being traded along The Belt and Road Initiative countries. To increase the qualities of Made in China, the developments of 'Spirit of the craftsman' and vocational education are emphasized and widely discussed. According to our opinion, measures and steps for the cultivating of spirit of craftsman in higher vocational education are discussed in this paper.

\section{THE RAISE AND FALL OF CHINESE CRAFTSMEN}

\section{A. Who Can Become a Craftsman}

Because the spirit of a craftsman can't exist when it is excluded from its owner, we can't ignore the silent craftsman, when we are discussing craftsmen spirit again.

The truth of ancient craftsmen is full of sadness for most of them, since they are at the bottom of the society of the ancient China. Due to the limitation of production tools, craftsmen had to carry out handicraft production which consumes a large amount of time and patience [2].

At the same time, artisan products are occupied and consumed by the ruling class, it is difficult for craftsman to get fare pay to maintain the survival of himself and his families. Therefore, the choice to engage in handicraft industry is often helpless.

Nowadays, we prize craftsmen for their perseverance, because they are only engaged in one business for their lifetime. But this character also make them hard to adapt to the change of society and hard to survival. It may be part of the reason why lots of excellent ancient skills are missed and without inheritance.

Because of the time consuming daily working for months and years, the lack of educational and the cruel rule of rulers, general craftsmen are restricted to a fixed business and hard to get out.

\section{B. Cultivation of Craftsman Skill}

It takes a lot of time for the study of craftsman's skill. This is not only a factor of running after excellence goals, but also obstacle factors to the skills of artisans.

Most of the craftsmanship is not clearly documented, and even difficult to be accurately expressed in language. On the one hand a craftsman takes a lot of work and is lack of time for detailed explanation; on the other hand even they are poor educated. The new comer of a skill has neither cultural basis, nor skill foundation. Self-understanding ability and Smart is very essential for the transmission and learning of craftsman's skill. 'Skill can never be speak out and only can be touched by clever brain'. As a result, only a handful of gifted apprentices are able to comprehend the essence of the craft and become the inheritors of the craft, after the course of years of trial and error,

Due to the difficulty of making a living, the owner of the handicraft skill is faced with the competition from peers, even the competition between the master and apprentice. Therefore the skill is carefully protected, and can only be taught to trusted young men or even his own son. To avoid the possible leakiness to son in law and his families, even daughters are not allowed to study her father's skill.

\section{Modern Chinese Craftsmen}

With the development of human society, craftsman can choose job and receive better education. A lot of young men refused to choose traditional business as their job and move to some new service occupation which is more leisure. On the other hand, society still need excellent craftsmen, although they call use all kind of tools and equipments to help them save physical power.

For developing China, there are brilliant modern craftsmen stars from all most every society field fortunately. The old saying is there are three hundred and sixty trades, and every trade has its master.

In the new historical period, the connotation of artisan spirit is the seriousness to their products and exquisite, the spirit of excellence, the persistent focus on and the responsibility stick to duty.

On the official website of CCTV news, Country's Craftsmen and their brilliant performance and achievements are posted and updated continually [3]. Only those who have great enthusiasm for the work they will do, and who are able to persevere for a long time, can become excellent craftsmen.

\section{REFLECTIONS ON THE DEVELOPMENT OF MODERN CRAFTSMAN SPIRIT}

It is seems that almost everything is changed to be more and more humanized. But the potential factors which have influenced the development of craftsmanship for hundreds of years have to be avoided.

Craftsman skills are the experiences origin from the production of thousands of years. Although it can't be accurately recorded with text or documents, the results of using these skills can be reproduced with a large probability. Scientific knowledge is the book knowledge in many people's opinion. In fact, scientific knowledge of mankind is obtained by the masters of Science from the subtle phenomenon after the constant thinking, continuous reproduction and sublimation.

Science and craftsman skill have been existed for thousands of years at the same time. When we are going to pick up the artisan spirit again, we should do a new thinking firstly. We should dialectically look at this problem. Science and craftsman skill are both rooted in the production practice. 
But science has been a considerable development, and craftsman skills are still in the original stage.

It is generally agreed that the craftsman skill and science knowledge are not overlapping. During a very long period of time, this option is correct. However from the beginning of 2016, the leading Weiqi players around this world are defeated by an artificial intelligence game program (AlafaGo). Demis Hassabis is the founder of DeepMind Technologies, which has developed Alpha go [4]. At the age of 4 years old, he began to play chess, and become a master player of chess at the age of 13. When he was 17 year old ,He entered University of Cambridge to study computer science. We can say that Demis Hassabis is both craftsman of Weiqi and scientist.

Alpha go proved that the deepest human skills can be studied by science knowledge. We can believe that other skills should also be able to be understood with the help of science and technology. Newest science and technology methods which can be used to study the secrete skill of craftsman are recommended in this paper as follows:

\section{A. Digital Multimedia Technology}

Digital multimedia are popularly used to the protection of intangible cultural heritage, since the most direct method is record their image, color and voice. High speed camera can catch enriched details and help us to study Opera, folk songs, local operas.

\section{B. Motion Capture Technology}

A lot of craftsman's craft is the precise movements or gestures, such as the Taijiquan and the martial arts. For this kind of crafts, they are traditionally recorded with secret graphic books. When it is taught, oral instruments are given to assistant the practice of crafts. If you only have the secret book, you are still unable to get learned.

Rokoko, a start-up company in Denmark has developed a Smartsuit Pro motion capture suit as shown in Fig. 3. The Smartsuit Pro suite will be 19 sensors scattered in the wearer's body parts, each sensor is equipped with 1 gyroscopes, accelerometers and photometer. Using the data from each sensor, the system algorithm can calculate the relative threedimensional position of each sensor. In order to dress comfortably, the data collector is lighter than an iPhone [5].

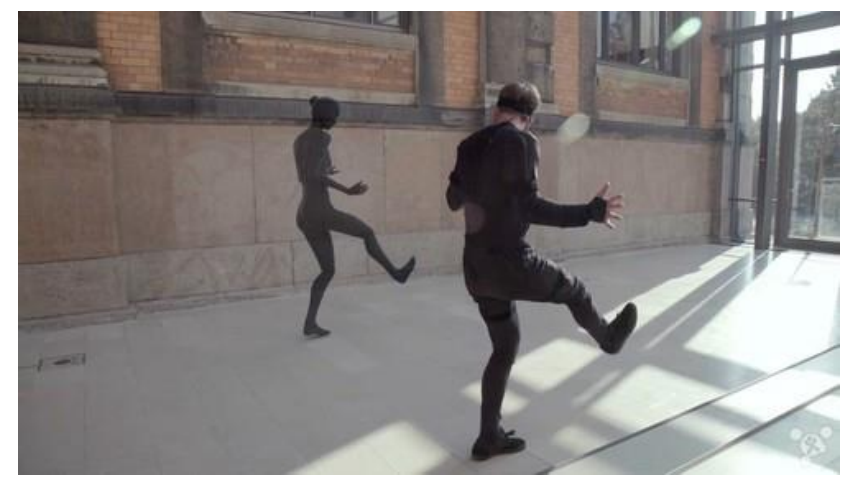

Fig. 3. Motion capture system Smartsuit

\section{Sensor Technology}

Some craftsman skills are embodied in the form of unique formula and combination. The craftsman is able to give the composition of the formula, the approximate weight of the addition, the order of giving addition, but can't give explain, but also the quantitative expression. By using sensor and analytical instruments, it is helpful to make components clear.

\section{Artificial Intelligence Technology}

Deep learning technology used in Alpha go, as well as other control theory and control engineering technology, computer science technology can be used as representation, recording and reproducing method of craftsman skill precisely [6-7]. For a long time, the goal of artificial intelligence is to performance better than the human being. But at least for the heritage of craftsman skills, learning and imitating artisans is the ultimate goal.

\section{CULTIVATING THE SPIRIT OF CRAFTSMEN IN HIGHER VOCATIONAL EDUCATION}

When we use the vocational education to cultivate the spirit of the craftsman, it is recommended to adopt the following measures:

\section{A. Engaging Top Craftsman As Guidance Teachers}

The cultivation of the craftsman spirit should be encouraged in the whole society [8]. In order to avoid becoming a hollowing slogan, the cultivation of the craftsman spirit must be combined with the specific skills. At present, the main needs of the craftsmen are supporting their family costs. To resolve the finance problem, you can use the power of the market, by organizing professional competition, and rewards the winner. The outstanding craftsmen to come to the market, finally change their status of day by day labor to maintain their livelihood. This kind of competition is constructive and full of positive power as least as good as entertainment program.

Even in some hot technology fields, there are still some problems. The winners of these games tend to receive more generous bonuses, as well as generous salaries. However, because these senior technicians are the treasure of the enterprise, they are often arranged a lot of important work, continue to work in the original post.

It is unrealistic to hire these people as formal teachers. In some cases, these masters will be recruited in a small range of apprentices, an bring a certain team. However, the effect is limited by objective conditions, which is not ideal. The reason is similar to that of the ancient craftsman.

A book has the copyright, a song has the copyright, A knowledge also has the property right, the craftsman's skill may also have the property right.

The difficulty is that it is not realistic for the craftsman to discover the inner experience and presented in a formalized form. So the commercial interests of craftsman experience can be purchased, and then explored by a professional team. Business operations by the business team to obtain economic 
benefits through the issuance of cultural products. This can greatly stimulate the enthusiasm of craftsmen to impart skills. It is also important to make the top craftsman a millionaire, at least as important as make an entertainment star to become a millionaire.

\section{B. Using AI Techniques To Modeling Top Craftsman's Skill}

After reaching an agreement on the transfer of top craftsman's skill, it is also faced with the challenge of how to transform the knowledge of craftsmen into the knowledge that can be understood and taught easily. A lot of skill only have very simple oral instruments and need a long time training. This situation greatly reduced the efficiency of skill learning. It also indirectly led to fewer and fewer young man willing to learn skills. In the process of AI modeling, craftsman and knowledge engineers, artificial intelligence engineers work together to improve the quality of the model, and eliminate small BUGs. This way is suggested to resolve the problem of 'Skill can only be sensed and can't be presented precisely'.

\section{Training plan classification}

After the completion of the acquisition of knowledge, professional personnel arrange training plan which is focused on a certain range of skill, in accordance with the principle of gradual increase the level of study.

\section{Training And Practices}

Essential training is the key to study a new skill. Please remember that human beings are the most complex system so far. Cognitive abilities of human beings, such as founding subtle perception and small differences, flexible using of experience, are difficult to be replaced by electronic devices which is relying on existing technology. The cost will be expensive, and devices can't meet the needs of a variety of scenarios. For example, alpha go need a huge team, and the calculating power of the computer is far more than just rely on the brain's ability to calculate mental arithmetic.

\section{E. Evaluation}

The evaluation process is particularly important in the process of the cultivation of the spirit of craftsman. Vocational education requires not only the relevant knowledge, but also the abilities to excellent application. Teachers need to score in this section. A better alternative is to ask a craftsman to grade the student's skill. Because the teacher's professional habit is to regard the students as learners, and craftsmen represent the standard from the market [9].

\section{F. Goal Of Vocational Education}

The goal of vocational education is provides a chance of system core skills learning, which is created and provided by craftsmen and researchers together.

Vocational education cut down the needed time for obtaining a craftsmen skill from about 10 years to 3years. On the other hand, it is necessary for students to reach a certain skill level as the goal. At present, Chinese higher vocational education is the "double certificate" education, which refers to the combination of academic education and the implementation of vocational qualification certificate system. Higher vocational qualifications should be expected, since personal teaching of skills can reach the level of the primary occupation.

\section{G. Lifetime vocational Study}

Some skills also need to have a long-term practice, even if there is a famous teacher. Vocational education needs to burden the responsibility of lifelong learning. As we know, the theory of vocational education is relatively simple; lifetime education is more important to increase the level of skills training. Higher vocational colleges should take the responsibility, not only to provide primary skills training and professional quality, but also to develop advanced skills. As a result of the use of artificial intelligence and knowledge engineering methods, the whole skill of craftsman was obtained and graded. Higher level of skills training, without increasing the educational resources and can also be opened normally. For those interested citizens, or students who have dropped out because of various reasons, lifelong learning has been a door always open.

\section{CONCLUSION}

When discussing the spirit of craftsman, we must review the factors that have profoundly affected the life and craftsmanship of the craftsman. Only removing these disadvantage and adverse effects, the spirit of craftsman can really be developed and provide powerful engine for the development of Made in China. The applications of the science and technology, such as artificial intelligence to assist the craftsmanship cultivation, are discussed in this paper. We also gives some suggestions on cultivate of the spirit of the craftsman for Vocational education.

The future direction is practice these measures and get more practical program for vocational education of city service.

\section{REFERENCES}

[1] X Qian, "Mechanical Engineering Development in Qin Dynasty", Journal of Northwest Sci-Tech University of Agriculture and Forestry,pp 132-134, 1995.

[2] RX Zheng, "An Analysis of the Craftsman Mythology in the Early Period of Ancient China", Journal of Northeast Normal University,pp 34-36, 2004.

[3] http://news.cctv.com/special/zgmsjz/all/dggj/index.shtml

[4] https://deepmind.com/

[5] https://www.rokoko.com/en/smartsuit-pro/

[6] D. Erhan, Y. Bengio, A. Courville, P. Manzagol, P. Vincent, S.Bengio, "Why Does Unsupervised Pre-training Help Deep Learning?", Journal of Machine Learning Research,vol 11,pp:625-660,2010

[7] R. Rada, H. Mili, E. Bicknell, M. Blettner,"Development and application of a metric on semantic nets",IEEE Transactions on Systems, Man, and Cybernetics,vol 19,pp 17-30,1989.

[8] Wu Yan , 'Spirit of the craftsman' needed to reshape the dairy industry",http://www.chinadaily.com.cn/china/201603/18/content_2394 2542.htm

[9] "Artisan spirit, the soul of vocational education" ,China Education Daily,2016-05-13 